\title{
Economic design of sleeve rotor induction motor using rotor ends
}

\author{
Omar S. Daif ${ }^{1}$, M. Helmy Abd Raouf ${ }^{2}$, Mohamed Adel Esmaeel ${ }^{3}$, Abd Elsamie B. Kotb ${ }^{1}$ \\ ${ }^{1}$ Department of Electrical Power and Machines, Faculty of Engineering, Al Azhar University, Cairo, Egypt \\ ${ }^{2}$ Department of Electrical Quantities Metrology, National Institute of Standards (NIS), Giza, Egypt \\ ${ }^{3}$ Department of Electrical Power and Machines, Faculty of Helwan Engineering, Helwan University, Cairo, Egypt
}

\begin{tabular}{l} 
Article Info \\
\hline Article history: \\
Received Jun 11, 2021 \\
Revised Sep 21, 2021 \\
Accepted Oct 18, 2021 \\
\hline Keywords: \\
Cylindrical coordinates \\
Equivalent circuit \\
Field equation \\
Induction machine \\
Motor performance \\
Rotor ends \\
Sleeve rotor
\end{tabular}

\section{Article Info}

Article history:

Received Jun 11, 2021

Revised Sep 21, 2021

Accepted Oct 18, 2021

Keywords:

Cylindrical coordinates

Equivalent circuit

Field equation

Motor performance

Sleeve rotor

\begin{abstract}
In this paper, the field analysis of the sleeve rotor induction motor (IM) is carried out taking the rotor ends into consideration. Here, the field system equations are derived using the cylindrical model with applying Maxwell's field equations. It is expected that, both starting and maximum torques will increase with taking the rotor ends than that without rotor ends. A simple model is used to establish the geometry of the rotor ends current density and to investigate the air gap flux density. The magnetic flux is assumed to remain radially constant through the very small air gap length between the sleeve and stator surfaces. Variation of the field in the radial direction is ignored and the skin effect in the axial direction is considered. The axial distributions of the air gap flux density, the sleeve current density components and the force density have been determined. The motor performance is carried out taking into account the effects of the rotor ends on the starting and normal operations. The sleeve rotor resistance and leakage reactance have been obtained in terms of the cylindrical geometry of the machine. These equivalent circuit parameters have been calculated and plotted as functions of the motor speed with and without the rotor ends.
\end{abstract}

This is an open access article under the $\underline{C C B Y-S A}$ license.

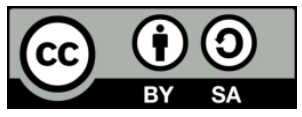

\section{Corresponding Author:}

Omar S. Daif

Department of Power and Electrical Machines, Faculty Engineering, Al Azhar University

4 Mohamad Riad St., from Ali Amin St., Nasr City, Cairo, Egypt

Email: omareng2006@gmail.com

\section{INTRODUCTION}

The machine of a sleeve rotor has a smooth conducting cylinder mounted on an iron backing cylinder which reduces the magnetic circuit reluctance to complete the flux bathes [1], [2]. The inner cylinder is used here, as a job of an iron core to decrease the effective air gap length as result of omitted rotor slots [3], [4]. It is expected that, the contribution of the force density to the developed torque with rotor ends will be higher than that without ends. The homogenous sleeve rotor construction allows higher rotational speeds [5], [6] compared to the similar wounded rotor. It is obvious that the contribution of the force density to the developed torque with rotor ends is higher than that without rotor ends.

The studies [7]-[9] have used the experimental results to predict the machine performance and determine the sleeve rotor equivalent circuit parameters after manufacturing the machine with some suggested data. Several studies [10]-[13] apply the analysis using Cartesian coordinates for special and very simple applications of the field equations to determine the circuit parameters. Some effects of secondary conducting sheet design on the motor performance are considered in [14], [15] but without taking the rotor end effect into account. 
In this paper, the cylindrical coordinates are used instead of the Cartesian coordinates to represent the machine geometry. The field analysis of suggested sleeve rotor induction machine is carried out, using Maxwell's field equations. The current density through the conducting sleeve cylinder is allowed to have axial and tangential components. The air gap flux density is assumed to be only radial component along a very small mechanical air gap length.

The magnetic field in the rotor end regions is determined by introducing longer and equivalent air gap length. The axial distribution of the air gap flux density as well as the sleeve rotor current density components are determined and plotted with and without sleeve rotor ends. The main motor characteristics are calculated and plotted as function of the slip with and without rotor ends.

A suggested and new technique, is applied here for determining the sleeve rotor equivalent circuit parameters. The equivalent sleeve resistance and leakage reactance are plotted as functions of the rotor speed with and without taking the rotor ends into consideration. This special technique appears the sleeve rotor skin effect through the axial sleeve rotor direction.

\section{FIELD ANALYSIS USING CYLINDRICAL COORDINATES}

A model of Figure 1 is suggested and used for applying field analysis on the sleeve rotor machine with taking the rotor ends into consideration. In this model, the following assumptions are introduced: i) stator windings are replaced by an equivalent current sheet of infinitesimal thickness carrying the stator electric loading as; ii) stator and rotor iron parts have infinitely permeability and zero conductivity; iii) current density through the conducting sleeve cylinder is allowed to have axial and tangential components; and iv) air gap flux density is assumed to be only radial component along the geometrical small air gap length, so the field variation in the radial direction is ignored.

An approximate estimation for the field outside the stator main region is introduced in the analysis by assuming a modified profile of the stator iron in the axial end regions. An inclined iron surface by an angle of $51^{\circ}$ is given in [16], [17] where the end air-gap length is increased as shown in Figure 2, then the model consists of three regions in axial direction. The main region is that of $-z_{s} \leq z \leq z_{s}$, which has air gap length $g_{s}=g_{o}+t_{c}$ with stator electric loading $\mathrm{A}_{s}$. The two end regions are $-\left(z_{s}+d\right) \leq z \leq-z_{s}$ and $z_{s} \leq z \leq\left(z_{s}+d\right)$, with the estimated (longer) air gap length, $g_{e}=g_{s}+0.5 d \tan 51^{\circ}$, with no stator electric loading.

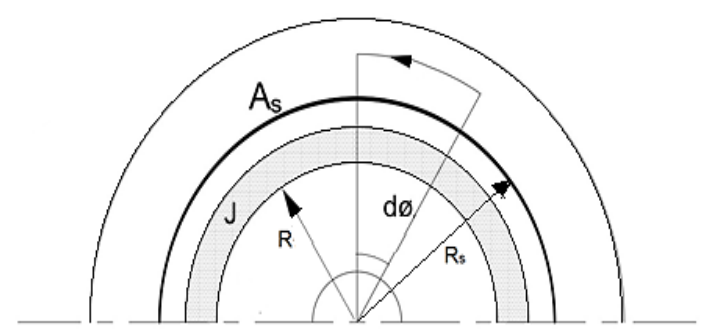

Figure 1. Model of sleeve-rotor induction machine

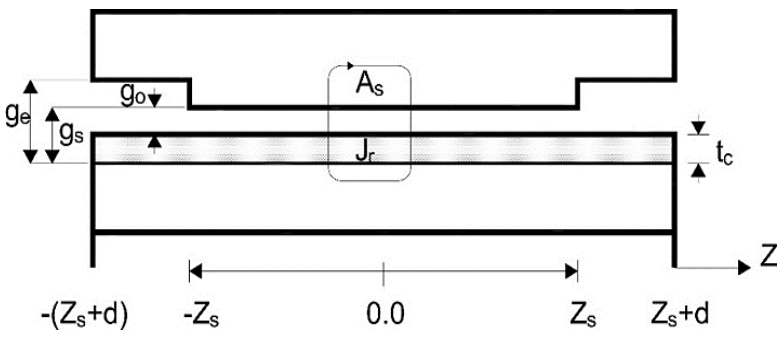

Figure 2. Modified model with longer air-gaps in axial end regions

The air gap flux density has a radial component $\mathrm{B}_{\mathrm{r}}$, while, the sleeve rotor current density components are axial and tangential components $J_{z}$ and $J_{\varphi}$, respectively [18]-[20].

$$
\vec{B}=B_{r} \cdot \vec{a}_{r}
$$

With applying the integral form of the Maxwell's first equation to a loop of Figure 1, with infinitesimal dimensions in the $\mathrm{r}-\varphi$ plane, yields

$$
B_{r}=j \frac{\mu_{o} R}{p g_{s}}\left\{A_{s}+J_{z} \cdot t_{c}\right\}
$$

where, $\mathrm{R}$ is the rotor radius, $\mu_{o}$ is the air gap permeability and $\mathrm{p}$ is the stator number of pole pairs.

The second Maxwell's [21]-[23] is applied to the closed loop of Figure 2, in z- $\varphi$ plane and from the continuity condition, the relation between $\varphi$ and z-components of the sleeve current density is (3). 


$$
J_{\varphi}=-j \frac{R}{p} \frac{d J_{z}}{d z}
$$

The axial current density component of the rotor along the active stator length in main region is governed by the following second order differential (4):

$$
\frac{d^{2} J_{z m}}{d z^{2}}-K_{m}^{2} J_{z m}=-C_{m}
$$

where, the complex quantities (5), (6),

$$
\begin{aligned}
& K_{m}^{2}=\frac{p^{2}}{R^{2}}-j \frac{\omega \sigma_{c} s \mu_{o} t_{c}}{g_{s}}, \\
& C_{m}=j \frac{\omega \sigma_{c} s \mu_{o}}{g_{s}} A_{s}
\end{aligned}
$$

with $\sigma_{c}$ is the sleeve conductivity, $\omega$ is the angular frequency, and s is the slip.

For the rotor end regions with increased air gap length $g_{e}$ and there is no stator excitation current sheet (i.e. the stator electric loading is finished here), the differential (4), is reduced to (7):

$$
\frac{d^{2} J_{z e}}{d z^{2}}-K_{e}^{2} J_{z e}=0.0
$$

where, the complex quantities of (6) and (7), are modified to be (8):

$$
\begin{aligned}
& K_{e}^{2}=\frac{p^{2}}{R^{2}}-j \frac{\omega \sigma_{c} s \mu_{o} t_{c}}{g_{e}} \\
& \text { and } C_{e}=0.0
\end{aligned}
$$

\section{SOLUTION OF THE FIELD EQUATIONS}

Solution of (4), for the main region of the model can be obtained and the axial current density component is (10),

$$
J_{z m}=P_{m} e^{k_{m} Z}+Q_{m} e^{-k_{m} Z}+\frac{C_{m}}{K_{m}^{2}}
$$

with the tangential current density component is (11).

$$
J_{\varphi m}=-j \frac{R k_{m}}{p}\left(P_{m} e^{k_{m} Z}-Q_{m} e^{-k_{m} Z}\right)
$$

Hence the radial flux density is (12),

$$
B_{r m}=j \frac{\mu_{o} R}{p g_{s}}\left\{A_{s}+J_{z m} t_{c}\right\}
$$

for the axial end regions, the solution may be governed by (13a), (13b), (14a), (14b), (15a), (15b):

$$
\begin{aligned}
& J_{z e 1}=P_{e 1} e^{k_{e} Z}+Q_{e 1} e^{-k_{e} Z} \\
& J_{z e 2}=P_{e 2} e^{k_{e} Z}+Q_{e 2} e^{-k_{e} Z} \\
& J_{\varphi e 1}=-j \frac{R k_{e 1}}{p}\left(P_{e 1} e^{k_{e 1} Z}-Q_{e 1} e^{-k_{e 1} Z}\right) \\
& J_{\varphi e 2}=-j \frac{R k_{e 2}}{p}\left(P_{e 2} e^{k_{e 2} Z}-Q_{e 2} e^{-k_{e 2} Z}\right) \\
& B_{r e 1}=j \frac{\mu_{o} R}{p g_{e 1}}\left\{A_{s}+J_{z e 1} t_{c}\right\} \text { and }
\end{aligned}
$$




$$
B_{r e 2}=j \frac{\mu_{o} R}{p g_{e 2}}\left\{A_{s}+J_{z e 2} t_{c}\right\}
$$

The conditions which are sufficient to determine completely the six integration constants $\mathrm{P}$ and $\mathrm{Q}$ of the three regions are: the first condition is based on the fact that, the axial current density must vanish at the edges of the sleeve ends.

$$
\text { at } z= \pm\left(z_{s}+d_{1}\right), J_{z e 1,2}=0
$$

The second condition is the continuity of both current density components $\left(J_{z}\right.$ and $\left.J_{\varphi}\right)$ across each axial interregional boundary, at $z= \pm z_{s}$.

$$
\begin{aligned}
& J_{z m}=J_{z e} \\
& J_{\varphi m}=J_{\varphi e}
\end{aligned}
$$

These six conditions are sufficient to determine completely the integration constants $\mathrm{P}$ and $\mathrm{Q}$. The boundary conditions (17) and (18) are applied and plotted in Figures 3(a) and 3(b), $\left(J_{o}=A_{s} / t_{c}\right)$.

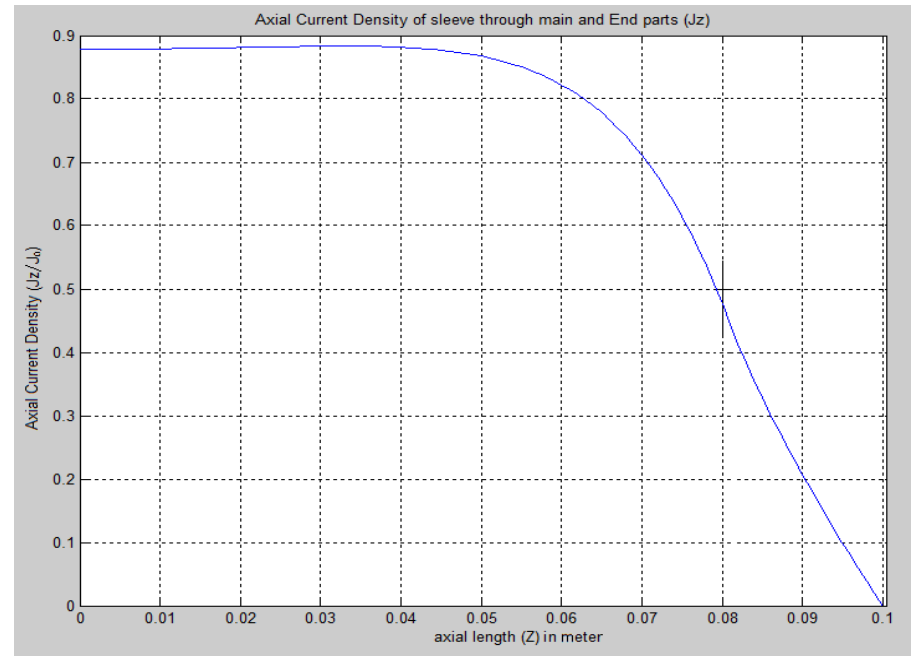

(a)

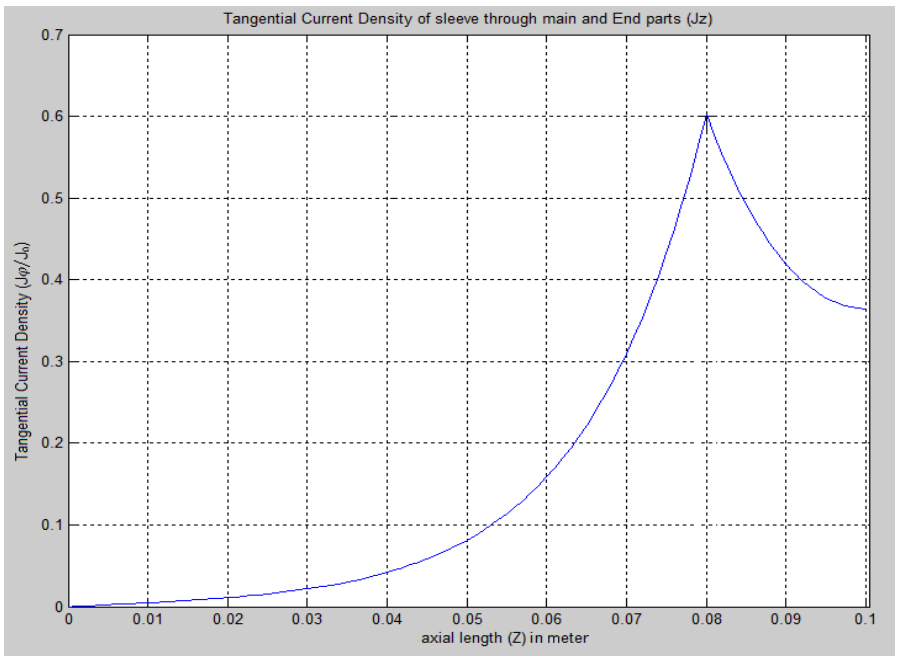

(b)

Figure 3. Continuity of current density through the axial interregional boundary of main rotor length with the rotor ends: (a) axial current density component and (b) tangential current density component 


\section{RESULTS OF CALCULATIONS}

Once the integration constants are determined, the air gap flux density and the sleeve rotor current density components for the three axial regions can be obtained. The normalized sleeve rotor current density components, $\mathrm{J}_{z}$ and $\mathrm{J} \varphi$ for main region of the model where $-z S \leq z \leq z S$, are distributed with and without rotor ends in Figures 4 and 5. The axial component of the sleeve rotor current density attains its maximum value when the tangential component reduces to zero. The axial distributions of the air gap flux density with and without rotor ends is shown in Figure 6, with the distribution is normalized by $B_{o}=\frac{\mu_{o} R}{P g_{s}} A_{s}$.

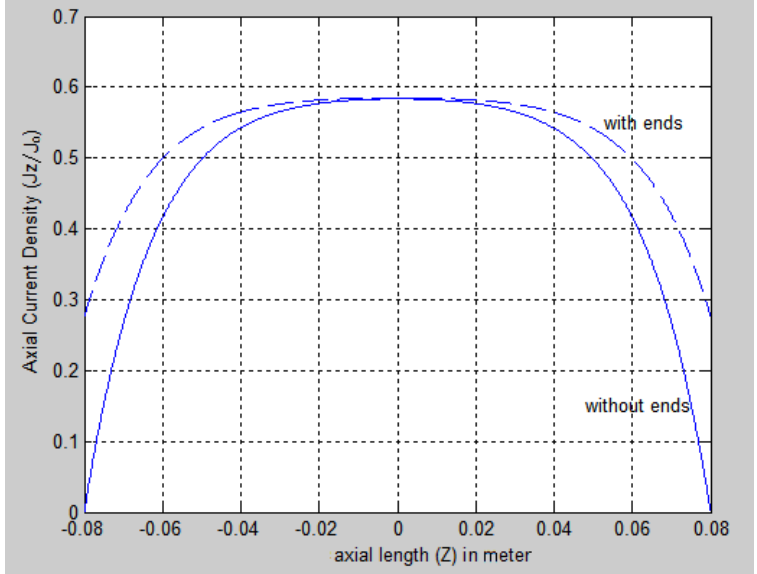

Figure 4. Axial rotor current density distribution through the main length for sleeve-rotor with and without rotor ends

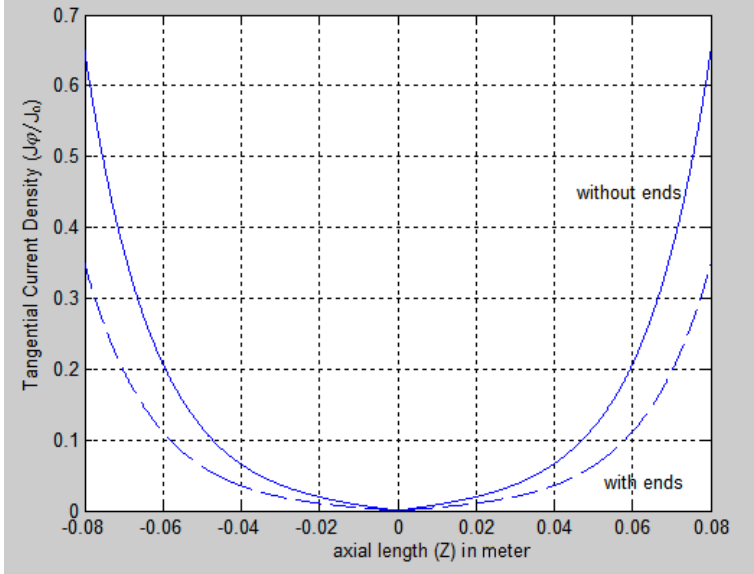

Figure 5. Tangential rotor current density distribution through the main length for sleeve-rotor with and without rotor ends

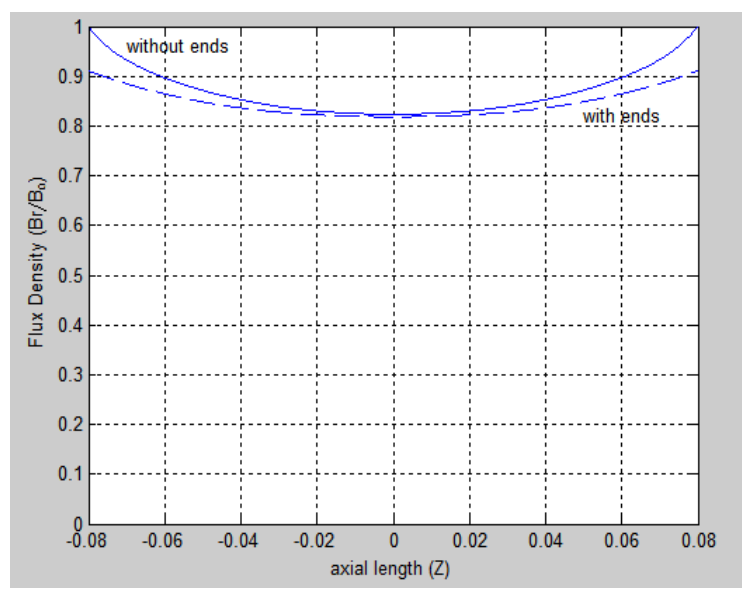

Figure 6. Air gap flux density distribution through the main length for sleeve-rotor with and without rotor ends

Generally, the difference between load and short circuit flux density is the immediate measure of the intensity of the rotor armature reaction. As a result of symmetry, the flux density as well as the tangential current density exhibit minimum values at the middle of the rotor, meanwhile the axial current density attains maximum. Hence, the axial rotor current density and the air gap flux density are known then the tangential force density per unit volume can then be determined as (19a):

$$
f_{\varphi}(z)=-\frac{1}{2} \operatorname{Re}\left\{J_{z m} \cdot B_{r m}\right\}
$$

The force density distribution is plotted in Figure 7 and normalized by (19b). 
$f_{o}=\frac{1}{2} \frac{\mu_{o} R}{p g_{s} t_{c}} A_{s}^{2}$

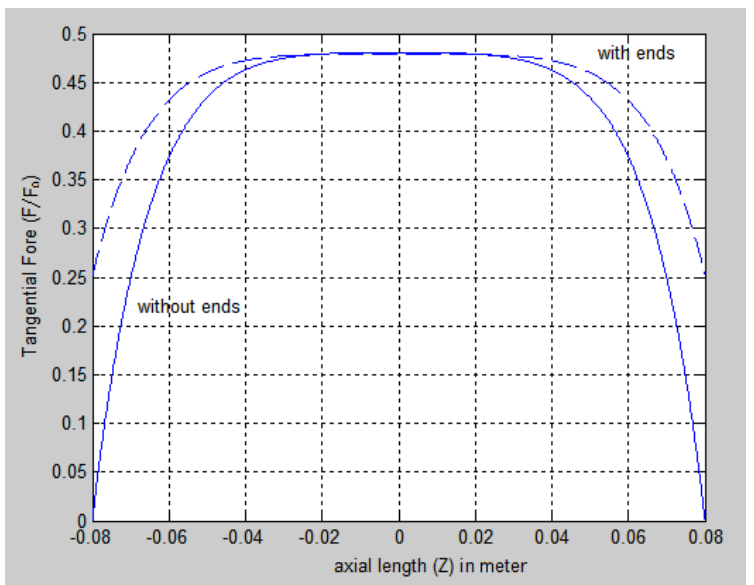

Figure 7. Force density distribution through the main length for sleeve-rotor IM with and without rotor ends

At normal speed, the maximum force density occurs in the middle of the rotor sleeve then its contribution to the developed torque will be large. At starting, the maximum force density appears near the rotor edges, here its effect on the starting torque will be weaker. For the case of rotor ends, the positions of minimum flux density and tangential current density as well as the maximum of axial current density move towards the out-hang regions. The higher force density occurs near the rotor ends, which affects both starting and maximum torque values. The total tangential force acting on the rotor can be obtained by integrating the force density over the sleeve volume. Then the developed torque can be obtained from the following integration:

$$
T=\int_{-z_{S}}^{z_{S}} 2 \pi R^{2} t_{c} f_{\varphi} d z
$$

Figure 8 shows the torque-speed characteristic for two rotors with different end dimensions. The reference value of the torque is then

$$
T_{o}=2 \pi R^{2} t_{c} z_{s} f_{o}
$$

The case of equal rotor ends improves the motor performance characteristics as all and raises the developed torque through the operating range. This is due to the current loops which close their paths within the sleeve end regions. It is obvious that the higher starting torque can be taken from the motor which has a sleeve-rotor with small ends.

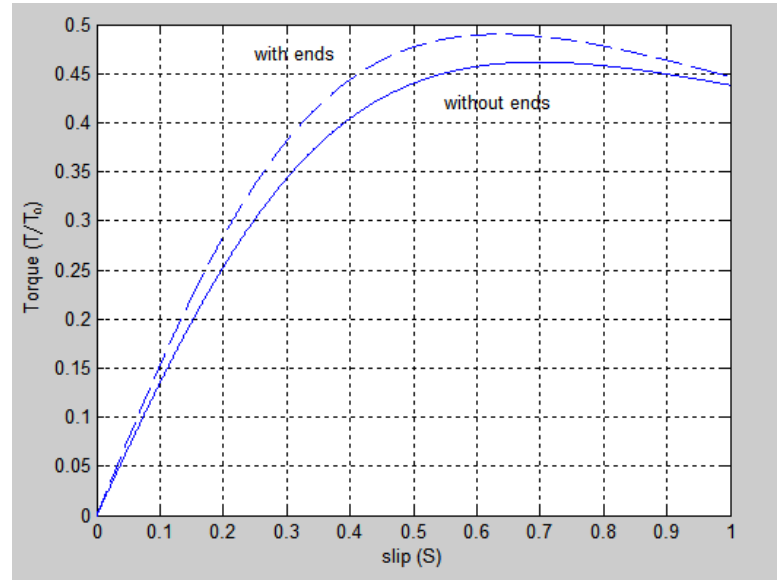

Figure 8. Torque vs slip for sleeve-rotor IM with and without rotor ends 
The torque-slip characteristics obtained with rotor ends is compared with that obtained without rotor ends as shown in Figure 8. The rotor end regions improve the motor torque characteristics, they increase the developed torque through the operating range of the machine. It is obvious, that the contribution of the force density to the developed torque with rotor ends is higher than that without rotor ends.

\section{EQUIVALENT CIRCUIT PARAMETERS}

The well-known equivalent circuit Figure 9, is proposed to represent the induced voltage across the magnetizing reactance $X_{m}$ in parallel with the rotor equivalent impedance. This rotor impedance, consists of a pure resistance $R_{r}$, in series with an imaginary element $j X_{r}$, which represents the rotor leakage reactance. Therefore, resistance, inductance and impedance are important parameters which should be determined and investigated [24]-[28].

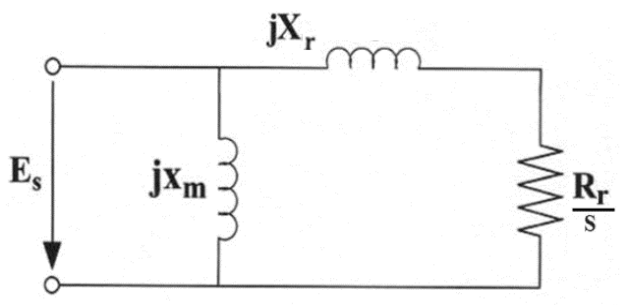

Figure 9. Air gap equivalent circuit

The mechanism of the sleeve leakage expresses the decoupling between the rotor and stator windings. In the sleeve rotor there are some current elements which close their paths within the active length. There are other paths will take the rotor ends as a job to the sleeve current at the rotor ends. Hence, it is expected that the sleeve leakage flux decreases as the width of the rotor end increases.

To determine the air gap impedance, it is necessary now to drive an expression for the stator induced voltage, using the flux linkage of the stator windings. The average flux density over the stator axial length is (21a),

$$
B_{\text {rav }}=\frac{1}{2 z_{S}} \int_{-z_{S}}^{z_{S}} B_{r}(z) d z=B_{o} \beta
$$

where, the complex coefficient $\beta$ has both real and imaginary parts $\beta_{r}$ and $\beta_{i}$, respectively (21b):

$$
\beta=\beta_{r}+j \beta_{i}
$$

Hence, the equivalent rotor current can be determined using the average of the axial current density component,

$$
J_{z a v}=\frac{1}{2 z_{s}} \int_{-z_{S}}^{z_{S}} J_{z}(z) d z=J_{o} G
$$

where, the complex coefficient $G$ has both real and imaginary parts $G_{r}$ and $G_{i}$, respectively (22b):

$$
G=G_{r}+j G_{i} T_{o}=2 \pi R^{2} t_{c} z_{s} f_{o}
$$

Also, the equivalent current of the sleeve rotor referred to the stator side is obtained in terms of the stator current $\mathrm{I}_{\mathrm{s}}$ as $(22 \mathrm{c})$ :

$$
I_{r}=G I_{s}
$$

Using the air gap power expressions and the voltage equation of the proposed circuit of Figure 9, the sleeve rotor impedance and the individual rotor equivalent circuit parameters can then be obtained in the forms:

$$
\begin{aligned}
& R_{r}=-\left(\frac{\beta_{r} \cdot s}{G \cdot G^{*}}\right) X_{m} \\
& X_{l r}=-\left(1+\frac{G_{r}}{G \cdot G^{*}}\right) X_{m}
\end{aligned}
$$


with the known magnetization reactance $X_{m}$ is $(23 c)$,

$$
X_{m}=\omega \frac{2 \mu_{o} m_{s} \pi R_{s} \cdot 2 z_{s}}{\pi^{2} p^{2} g_{s}} \cdot\left(W_{s} K_{w}\right)^{2}
$$

The (23) enable the sleeve resistance and the leakage reactance to be determined for any sleeve rotor machine design data, as functions of the motor speed. The obtained equivalent circuit parameters provide useful guidelines for any designer. It is very helpful in selecting a suitable sleeve dimension which satisfy the required and specified machine characteristics. Also, the individual equivalent circuit parameters of the sleeve are directly affected by the dimensions of the rotor ends.

The sleeve resistance without rotor ends is affected by the motor speed so that it attained its higher value at starting. The rotor resistance is plotted in Figure 10 as a function of speed, with the sleeve end resistance is inherently included. With the rotor ends, the eddy currents flow easy to close their paths in the rotor end regions, indicating lower sleeve resistance. This is due to the more current elements which close their paths within the sleeve rotor ends. Figure 11 shows the rotor leakage reactance for two sleeves as function of the motor speed. The decoupling between the rotor and stator windings increases without rotor ends, hence more current elements close their paths within the sleeve active length with higher leakage reactance. It is evident that, the comparatively large rotor ends lead to increase the coupling between the stator winding and the sleeve rotor cylinder which decreases the rotor reactance.

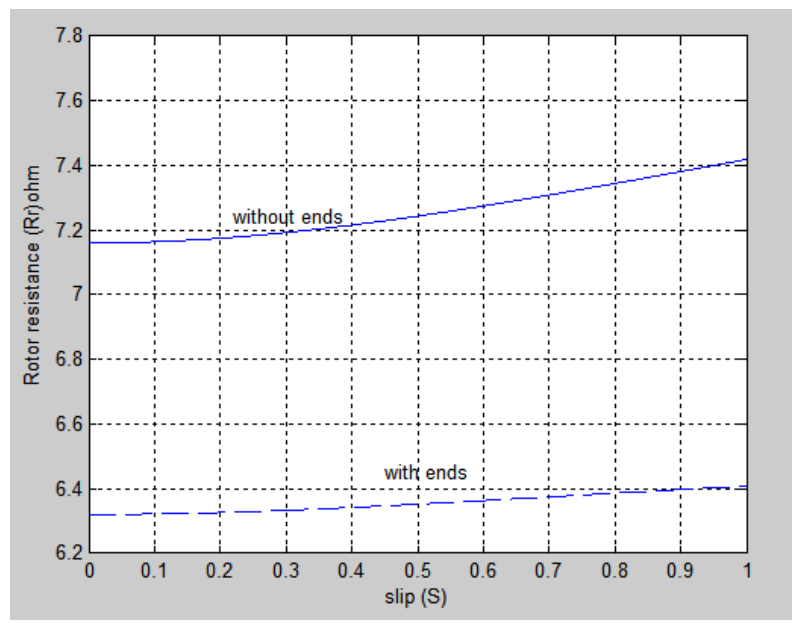

Figure 10. Rotor resistance ( $\mathrm{Rr}$ ) vs slip for sleeve-rotor IM with and without rotor ends. Thick line is without and thin one is with rotor ends

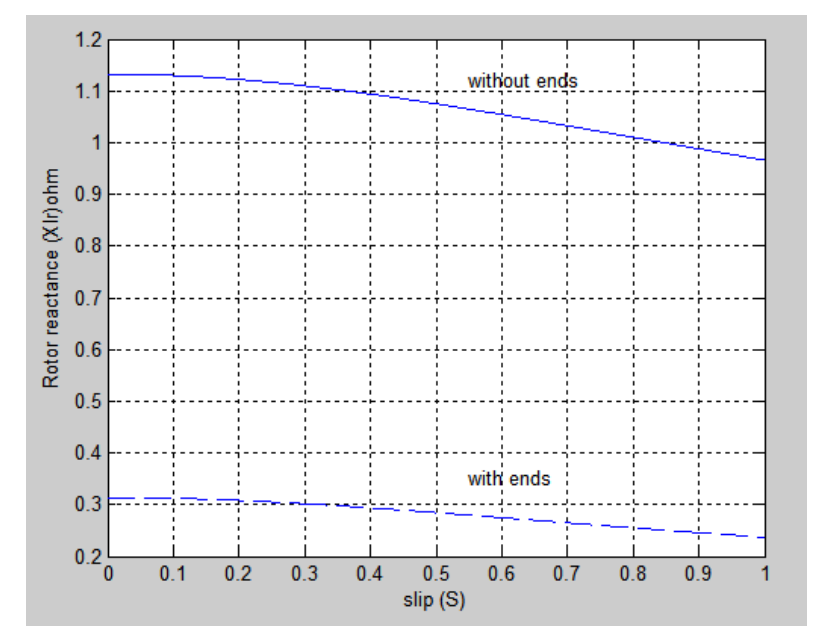

Figure 11. Rotor reactance (Xlr) vs slip for sleeve-rotor IM with and without rotor ends. Thick line is without and thin one is with rotor ends 


\section{CONCLUSION}

Analysis of a sleeve rotor induction machine with rotor ends using cylindrical coordinates restores the geometry of the machine. In the present work; the sleeve rotor ends are taken into account through different approaches. The main approach is the machine performance. Firstly, the analysis deals with the machine performance when the field outside the stator iron length is ignored. The second approach considers the effects of the magnetic field in the regions adjacent to the edges of the stator iron on the motor performance. It is obvious that the contribution of the force density to the developed torque with rotor ends is higher than that without rotor ends. The higher force density occurs near the rotor ends, which affects both starting and maximum torque values. The rotor end regions improve the motor characteristics, and increase the developed torque through the operating range of the machine. Also, it is evident that both starting and maximum torques increase with increasing the rotor ends length.

Taking the ends effect into consideration with small sleeve rotor ends leads to an appreciable leakage reactance in the normal operating range. This comparatively high value of rotor leakage reactance is due to the nature of the sleeve leakage mechanism, which is expressing the decoupling between the rotor and the stator windings. The effect of the sleeve end resistance is inherently included in the suggested derived expression for the equivalent rotor resistance, which increases as the sleeve end decreases. It is evident that the current displacement phenomenon with the suggested special technique proves the sleeve rotor skin effect through the axial direction of the rotor conducting sleeve.

\section{REFERENCES}

[1] A. B. Kotb, "Sleeve-rotor induction motor with rotor ends," in Record of the fifth International Middle East Power Conference MEPCON 97, 1997, pp. 170-175.

[2] M. Shalaby, "Phase-angle control of the repulsion/drive force ratio in two-phase linear induction motor with nonferromagnetic secondary," IEE Proceedings B: Electric Power Applications, vol. 132, no. 2, pp. 81-86, 1985, doi: 10.1049/ip-b.1985.0010.

[3] A. B. Kotb, "The effects of secondary sheet design on the performance of sleeve-rotor induction motor," in $A E C$, 1989, pp. 47-55.

[4] B. V Jayawant and P. J. Parr, "Sleeve-rotor induction motors for control applications," IEEE Transactions on Power Apparatus and Systems, vol. PAS-88, no. 7, pp. 1103-1114, Jul. 1969, doi: 10.1109/TPAS.1969.292511.

[5] Y. Le and K. Wang, "Design and optimization method of magnetic bearing for high-speed motor considering eddy current effects," IEEE/ASME Transactions on Mechatronics, vol. 21, no. 4, pp. 2061-2072, 2016, doi: 10.1109/TMECH.2016.2569822.

[6] A. B. Kotb and F.M. El-Lithy, "Operation of two- phase sleeve - rotor induction motor from 1-phase supply using phase angle control," in AEIC, 1993, pp. 164-176.

[7] C. W. Blachford, "Induction cup parameters from electromagnetic field theory and experimental analysis," IEEE Transactions on Power Apparatus and Systems, vol. 84, no. 11, pp. 1089-1093, Nov. 1965, doi: 10.1109/TPAS.1965.4766140.

[8] B. L. Fuller and P. H. Trickey, "Equivalent drag cup resistance," Transactions of the American Institute of Electrical Engineers. Part III: Power Apparatus and Systems, vol. 81, no. 3, pp. 285-290, Apr. 1962, doi: 10.1109/AIEEPAS.1962.4501315.

[9] C. A. C. Wengerkievicz et al., "Estimation of three-phase induction motor equivalent circuit parameters from manufacturer catalog data," Journal of Microwaves, Optoelectronics and Electromagnetic Applications, vol. 16, no. 1, pp. 90-107, Mar. 2017, doi: $10.1590 / 2179-10742017$ v16i1873.

[10] R. H. Frazier, "Analysis of the drag-cup A-C tachometer by means of 2-phase symmetrical components," Transactions of the American Institute of Electrical Engineers, vol. 70, no. 2, pp. 1894-1906, Jul. 1951, doi: 10.1109/T-AIEE.1951.5060647.

[11] S. M. WALY, "Correspondence: derivation of the torque equation for a two phase drag-cup servomotor," Electric Machines \& Power Systems, vol. 5, no. 4, pp. 371-377, Jul. 1980, doi: 10.1080/07313568008955417.

[12] S. M. Waly and W. Hosni, "End effect in 2-phase drag-cup servomotors," Electric Machines and Power Systems, vol. 5, no. 2, pp. 179-185, Mar. 1980, doi: 10.1080/07313568008955401.

[13] R.-J. Wang and M. J. Kamper, "Calculation of eddy current loss in axial field permanent-magnet machine with coreless stator," IEEE Transactions on Energy Conversion, vol. 19, no. 3, pp. 532-538, Sep. 2004, doi: 10.1109/TEC.2004.832043.

[14] O. S. Daif, M. H. A. Raouf, and A. B. Kotb, "Field analysis, distribution and performance of sleeve rotor induction motor taking the sleeve rings into consideration," International Journal of Recent Technology and Engineering, vol. 9, no. 1, pp. 838-842, May 2020, doi: 10.35940/ijrte.F8017.059120.

[15] A. B. M. Elayat, S. A. Zaid, and A. B. Kotb, "Field analysis and equivalent circuit parameter of eddy current rotor induction motor with, without and closed iron backing," Int. J. of Advan. Sci. and Tech., vol. 29, no. 3, pp. 14109-14122, Mar. 2020.

[16] H. Weh, H. Mosebach, and H. May, "Analysis and characteristics of the disk-rotor induction motor," Electric Machines and Power Systems, vol. 1, no. 1, pp. 87-98, Jan. 1976, doi: 10.1080/03616967608960019.

[17] A. B. Kotb, "Disc-rotor induction motor with mechanical speed-control," in Sci. Boll. Fac. Eng. Ain Shams Univ, No. 4., 1996.

[18] A. Menessy, M. Elwany, and A. Kotb, "Derivation of the circuit parameters for a sleeve rotor induction machine," Journal of AlAzhar University Engineering Sector, vol. 14, no. 51, pp. 553-558, Apr. 2019, doi: 10.21608/auej.2019.33706.

[19] Y. Liu, W. Liu, and N. Cheng, "Magnetic field and eddy current analysis of permanent magnet eddy current coupling," in 2015 IEEE International Conference on Information and Automation, Aug. 2015, pp. 2817-2822, doi: 10.1109/ICInfA.2015.7279766.

[20] M. Ahmed, A. B. Kotb, and M. Zaher, "Field analysis and equivalent circuit arameters of disc-rotor induction motor," The International Conference on Electrical Engineering, vol. 5, no. 5, pp. 1-15, May 2006, doi: 10.21608/iceeng.2006.33625.

[21] A. Hughes and Bill Drury, Electric Motors and Drives, 5th ed. Elsevier, 2019.

[22] S. K. Mukerji, A. S. Khan, and Y. P. Singh, Electromagnetics for Electrical Machines. CRC Press, 2018.

[23] P. Witczak, "The finite element analysis of the magnetic vibrations in the induction motor," in Electric and Magnetic Fields, Springer (US), 1995, pp. 143-146.

[24] M. H. A. Raouf, "Design, implementation, and characterization of a new resistance box fabricated with fifteen outputs decades," Measurement: Journal of the International Measurement Confederation, vol. 101, pp. 206-210, Apr. 2017, doi: 10.1016/j.measurement.2017.01.038. 
[25] M. H. A. Raouf, K. T. Kim, and M. S. Kim, "Measurement of capacitance and resistance using two perfectly synchronized voltage sources," Measurement: Journal of the International Measurement Confederation, vol. 60, pp. 174-177, Jan. 2015, doi: 10.1016/j.measurement.2014.10.011.

[26] M. H. A. Raouf, A. Eliwa Gad, E. S. S. A. Said, and M. A. Elwany, "Fully automated inductance measuring system using new fabricated inductance box," Mapan - Journal of Metrology Society of India, vol. 32, no. 3, pp. 199-205, Apr. 2017, doi: $10.1007 / \mathrm{s} 12647-017-0210-\mathrm{z}$.

[27] A. Petrov, I. Plokhov, A. Rassolkin, T. Vaimann, A. Kallaste, and A. Belahcen, "Adjusted electrical equivalent circuit model of induction motor with broken rotor bars and eccentricity faults," in 2017 IEEE 11th International Symposium on Diagnostics for Electrical Machines, Power Electronics and Drives (SDEMPED), Aug. 2017, pp. 58-64, doi: 10.1109/DEMPED.2017.8062334.

[28] B. Nasir, "An Accurate Determination of Induction Machine Equivalent Circuit Components," Proceedings of the Proceedings of the 1st International Multi-Disciplinary Conference Theme: Sustainable Development and Smart Planning, IMDC-SDSP 2020, Cyperspace, 28-30 June 2020, 2020, doi: 10.4108/eai.28-6-2020.2297941.

\section{BIOGRAPHIES OF AUTHORS}
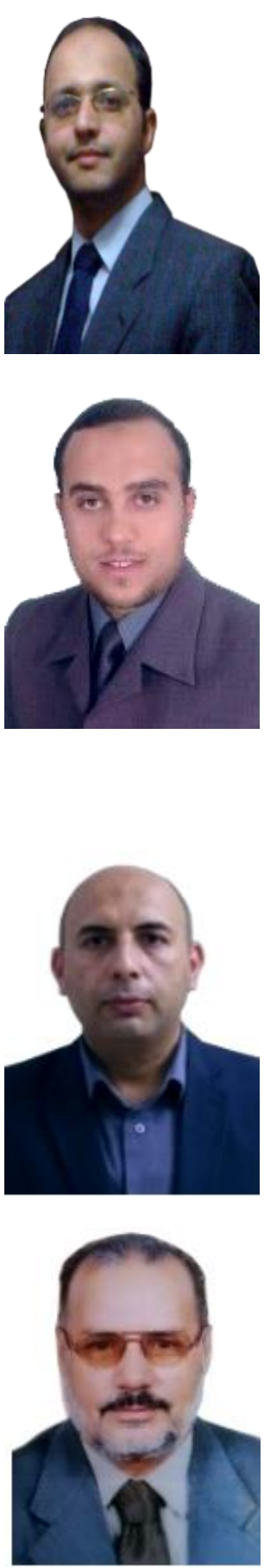

Omar S. Daif (iD $\mathrm{gl}$ SC $\mathrm{P}$ received the B.Sc. and the M.Sc. in Electrical Engineering from the Faculty of Engineering, Al-Azhar University, Cairo, Egypt in May 2009 and May 2018, respectively. In 2012 he became senior engineer of Testing Department at Cairo Oil Refining Company (CORC), Egypt. Since 2013, he has been a Head of Department of the Electrical service. From 4/2014 until now he works as summer training lecturer and instructor for Electrical courses at CORC training Department. He works in design and build 2 main substations (11/0.4 KV - 4MVA) and upgrade one main substation (66/11 KV - 130MVA). His research interests are mainly in the electrical machines and Energy Efficiency. He can be contacted at email: omareng2006@gmail.com.

M. Helmy Abd Raouf (D) SC P received the B.Sc., the M.Sc., and the Ph.D. in Electrical Engineering from the Faculty of Engineering, Al-Azhar University, Cairo, Egypt in May 2001, January 2005 and 2007, respectively. In 2018 he became full Professor. He joined the National Institute of Standards (NIS), Egypt, in 2003. From 4/2010 to 4/2011 he was Post - Doctor at Korea Research Institute of Standards and Science (KRISS), Deajeon, South Korea. Since 2013, he has been a Head of Department of the Electrical Quantities Metrology at NIS. Since 2016, he is the vice chair, of the Technical Committee for Electricity and Magnetism (TC-EM) of AFRIMETS, the intra-Africa metrology system, and the Egyptian delegate to the Consultative Committee for Electricity and Magnetism (CCEM) of the International Committee for Weights and Measures (CIPM). His research interests are mainly in the electrical machines and metrology of the electrical quantities such as capacitance, inductance, resistance, impedance and AC-DC measurements. He published more than 40 papers in refereed scientific journals and has 6 patents. He teaches some courses in electrical engineering. He can be contacted at email: mohammed.helmy@nis.sci.eg. ID: 2147483647.

Mohamed Adel Esmaeel Salama (D) I8I SC P received the B.Sc., M.Sc., and Ph.D. in 2004, 2009, and 2012 respectively from Helwan University and AL-Azhar university. He works as a lecturer for the Faculty of Helwan Engineering and Technology, Helwan University, Cairo, Egypt. His research interests include renewable energy, electrical machines, power electronic, photovoltaic, energy-storage applications, and space power applications. He can be contacted at email: Mohamed.adel.80@h-eng.helwan.edu.eg.

Abd Elsamie B. Kotb (D) SC P Professor of Electrical Machines, Faculty of Engineering Al-Azhar University. His research interests are mainly in the electrical machines and their applications. He can be contacted at email: kotb4545@yahoo.com. 